\title{
Improved estimation of mineral and fluid volumetric concentrations in thinly bedded carbonate formations
}

\author{
Zoya Heidari ${ }^{1}$, Carlos Torres-Verdín², and William E. Preeg ${ }^{3}$
}

\begin{abstract}
We recently introduced new petrophysical and compositional methods for joint interpretation of multiple conventional well logs. These inversion-based methods are suited for petrophysical interpretation of rock formations that exhibit complex solid composition, include thin beds, and are subject to mud-filtrate invasion. They combine nuclear and resistivity logs to assess porosity and volumetric/weight concentrations of mineral and fluid constituents, and are ideal for the quantitative interpretation of carbonate formations. We document the successful application of the newly introduced inversion-based interpretation methods to three carbonate formations. Interpretation results are compared to those obtained with commercial software and core/ X-ray diffraction (XRD) data whenever available. For two of the carbonate field examples where XRD data are available, nonlinear joint inversion of well logs improves the assessment of porosity by more than $30 \%$ and up to $100 \%$ in the presence of thin beds when compared to conventional interpretation methods.
\end{abstract}

\section{INTRODUCTION}

A preceding paper (Heidari et al., 2012) introduced three new inversion-based methods to estimate porosity and volumetric/ weight concentrations of mineral and fluid constituents in thinly bedded formations with complex solid composition. The focus of this paper is the application of the previously introduced methods to the petrophysical evaluation of carbonate formations. Conventional compositional evaluation of carbonate formations from well logs includes commercial multimineral linear/quasilinear methods (Mayer and Sibbit, 1980; Quirein et al., 1986; Doveton, 1994;
Rabaute et al., 2003), historical matrix identification (MID) crossplots (Clavier and Rust, 1976; Schlumberger, 2009), elemental spectroscopy (Herron and Herron, 1996; Herron et al., 2002), gamma-ray (GR) spectroscopy, and core measurements (i.e., Xray diffraction [XRD]) and core measurements of elemental chemistry of the solids such as Fourier transform infrared transmission (FTIR) spectroscopy and X-ray fluorescence (XRF). Techniques such as MID crossplots are unreliable and no longer common practice in formations with complex lithology.

Heidari et al. (2012) show that estimation algorithms included in commercial multimineral software are not always reliable in the presence of complex solid composition, thin beds, and mud-filtrate invasion. Likewise, neutron-capture spectroscopy and GR spectroscopy measurements can be affected by shoulder beds, which significantly influence the assessment of mineralogy in thin beds. Core measurements are often regarded as the most accurate reference for petrophysical and compositional assessment. However, they are limited to small and sparse samples along the wellbore, which may not be representative of reservoirs with pervasive heterogeneity. Additionally, XRD and FTIR spectroscopy measurements do not always provide consistent evaluation of some minerals such as clay and quartz (Sondergeld et al., 2010). The inversion-based interpretation methods introduced by Heidari et al. (2012) were successfully tested on challenging synthetic data sets, and are suitable for the petrophysical and compositional assessment of highly heterogeneous formations, e.g., carbonates and hydrocarbon-bearing shale.

Among the three inversion-based interpretation methods introduced by Heidari et al. (2012), the first method takes into account the effect of radial distribution of fluid saturation on well logs due to invasion. The second method consists of two steps: (1) separate inversion of individual well logs to assess bed physical properties, and (2) joint inversion of bed properties to estimate formation petrophysical properties. This latter method is best suited for thinly bedded formations where mud-filtrate invasion is negligible. The

\footnotetext{
Manuscript received by the Editor 18 October 2012; revised manuscript received 10 February 2013; published online 28 June 2013.

${ }^{1}$ Texas A\&M University, Harold Vance Department of Petroleum Engineering, College Station, Texas, USA. E-mail: Zoya@pe.tamu.edu.

${ }^{2}$ The University of Texas at Austin, Department of Petroleum and Geosystems Engineering, Austin, Texas, USA. E-mail: cverdin@mail.utexas.edu.

${ }^{3}$ Private consultant, Austin, Texas, USA. E-mail: wpreeg@austin.rr.com.

(C) 2013 Society of Exploration Geophysicists. All rights reserved.
} 
third method is a depth-by-depth inversion technique that is suitable for the interpretation of rock formations with thick beds and complex solid composition.

The second estimation method introduced by Heidari et al. (2012), referred to as fast nonlinear joint inversion of bed physical properties (bed-by-bed nonlinear joint inversion), estimates bed properties by inverting each log independently to explicitly reduce shoulder-bed effects. Next, it uses Schlumberger's commercial software, SNUPAR (Mark of Schlumberger), to assess porosity and volumetric/weight concentrations of mineral constituents using as input all bed physical properties separately inverted from each log. Similarly, the depth-by-depth joint inversion method transforms each well log into physical properties of formations without correction for shoulder-bed effects and then invokes SNUPAR (Mark of Schlumberger) to assess petrophysical and compositional properties.

The following sections document the implementation of the above described inversion-based petrophysical and compositional interpretation methods to three challenging carbonate field examples.

\section{METHOD}

The choice of carbonate examples was based on their complex solid composition and presence of thin beds, where conventional interpretation methods are often unreliable. Interpretation is performed with two of the inversion-based methods introduced by Heidari et al. (2012): (1) depth-by-depth nonlinear joint inversion, and (2) bed-by-bed nonlinear joint inversion.

Carbonate formations studied in this paper consist of quartz, calcite, dolomite, clay minerals, and heavy minerals such as siderite. We observe negligible separation between apparent resistivity logs with different radial lengths of investigation, which is an indication of either negligible or very deep mud-filtrate invasion (Figures 1, 6, and 7). This behavior prompts us not to include explicit corrections of well $\operatorname{logs}$ for mud-filtrate invasion effects in the interpretation.

Bed-boundary locations are needed in the implementation of bedby-bed nonlinear inversion and are detected by the inflection points of density and photoelectric factor (PEF) logs. In addition to bedboundary locations, the choice of initial guess is important when the inversion is underdetermined (when there are more unknown properties than measurements). In the case of underdetermined

Table 1. Carbonate field example no. 1: Summary of assumed Archie's parameters and matrix, fluid, and formation properties.

\begin{tabular}{lcc} 
Variable & Value & Units \\
\hline Winsauer factor in Archie's equation, $a$ & 1 & - \\
Archie's porosity exponent, $m$ & 2.5 & - \\
Archie's saturation exponent, $n$ & 3 & - \\
Connate-water salt concentration & 230 & $\mathrm{kppm} \mathrm{NaCl}$ \\
Water density & 1 & $\mathrm{~g} / \mathrm{cm}^{3}$ \\
In situ oil density & 0.98 & $\mathrm{~g} / \mathrm{cm}^{3}$ \\
Formation temperature & 320 & ${ }^{\circ} \mathrm{F}$ \\
Wet clay density & 2.81 & $\mathrm{~g} / \mathrm{cm}^{3}$ \\
Wellbore radius & 15.5 & $\mathrm{~cm}$ \\
\hline
\end{tabular}

inverse problems, Heidari et al. (2012) suggested using (1) the results obtained with depth-by-depth nonlinear joint inversion of well logs, or (2) core measurements, rock cuttings, or geologic information as initial guess for bed-by-bed nonlinear inversion to avoid trapping into local minimums and to expedite convergence.

In field example no. 1, which represents an underdetermined problem, we implement depth-by-depth and bed-by-bed joint inversion of well logs to assess petrophysical and compositional properties and compare the results against those obtained with commercial software. Results obtained with the depth-by-depth joint inversion method are used as initial guess for the bed-by-bed inversion method. In field example nos. 2 and 3, we only implement bedby-bed nonlinear joint inversion with different criteria to choose the initial guess. In field example no. 2, the initial guess for inversion is based on core measurements to reduce nonuniqueness in the estimation. Field example no. 3 represents an even-determined inverse problem whereby the inversion is initialized with constant properties across all beds.

Relative error/improvement of results reported for the three field examples is calculated via

$$
\text { Relative error } / \text { Improvement }=\left|\frac{p_{i, \text { ref }}-p_{i}}{p_{i, \text { ref }}}\right| \times 100 \%,
$$

where $p_{i, \text { ref }}$ and $p_{i}$ designate reference and estimated parameters, respectively. Reference parameters can be core measurements of estimated parameters, for instance.

\section{FIELD EXAMPLE NO. 1}

Field example no. 1 considers a thinly bedded depth interval in a carbonate formation. The well was drilled with oil-base mud $(\mathrm{OBM})$ and well $\log$ s were sampled at a rate of $0.15 \mathrm{~m}(0.5 \mathrm{ft})$; XRD measurements indicate presence of quartz, dolomite, calcite, and minor clay minerals (i.e., assumed to be chlorite). Presence of thin beds in addition to complex solid composition significantly affects the accuracy of estimated petrophysical and compositional properties. The objective of this field example is to quantify the reliability of three interpretation methods: (1) nonlinear depth-bydepth inversion of well logs, (2) nonlinear bed-by-bed inversion of well logs, and (3) linear/quasilinear commercial multimineral software.

Table 1 lists the assumed Archie's parameters and matrix, fluid, and formation properties, all of which were verified with core measurements. Clay type is assumed to be chlorite (i.e., a combination of magnesium-based and iron-based chlorite). The assumed clay type was crossvalidated by matching available well logs with their numerical simulation across pure shales. Well logs input to the joint inversion are array induction resistivity, PEF, density, and neutron porosity. Sonic logs are used for crossvalidation of inversion results. We did not use the GR $\log$ in the joint inversion due to uncertainty in quantifying Uranium (U), Thorium (Th), and Potassium (K) concentration of pure minerals in the formations. Unknown properties in inversion-based interpretation methods are total porosity, water saturation, and volumetric concentrations of quartz, dolomite, calcite, and clay. This example of interpretation constitutes an underdetermined inversion problem. Accordingly, results obtained with commercial software are used to initialize the depth-by-depth nonlinear joint inversion to avoid trapping into local minimums. 
Figure 1 compares measured well logs against their numerical simulations obtained using final results from depth-by-depth nonlinear joint inversion. The same figure describes the volumetric concentrations of minerals and fluids obtained with commercial software and depth-by-depth nonlinear joint inversion of well logs. Relative data misfits are $4.62 \%, 3.06 \%, 0.70 \%$, and $0.44 \%$ for electrical conductivity, PEF, density, and neutron porosity logs.

Figure 2 compares results obtained with depth-by-depth nonlinear joint inversion against core/XRD measurements and results obtained with commercial software. Estimated petrophysical and compositional properties are total porosity, total water saturation, solid volumetric concentration of quartz, calcite, dolomite, and clay. Depth-by-depth nonlinear joint inversion improves the assessment of porosity by approximately $15 \%$. Although both these methods are based on depth-by-depth joint inversion of logs, depth-by-depth nonlinear joint inversion gives rise to accurate estimates of depthby-depth physical properties by taking into account the chemical composition and volumetric concentration of each mineral in the formation.

There are two zones with high PEF values (higher than $5 \mathrm{~b} / \mathrm{e}$ ), which cannot be reproduced by numerical simulations (Figure 1) because none of the assumed minerals in the model exhibits photoelectric factors higher than $5 \mathrm{~b} / \mathrm{e}$. Because of this, we also observe fluctuations in the assessment of petrophysical and compositional properties in the relative depth interval from $10.06 \mathrm{~m}(33 \mathrm{ft})$ to $11.28 \mathrm{~m}(37 \mathrm{ft})$ shown in Figure 2.
Based on the comparison of measured logs against their numerical simulations, we infer that (1) there is either a heavy mineral in the formation which is not reported in XRD measurements, or (2) well logs are not properly corrected for presence of barite in the drilling mud. As an aside, the second left track of Figure 1, confirms the limitation of array-induction resistivity logs in measuring rock electrical resistivities higher than $2000 \mathrm{ohm}-\mathrm{m}$ in this carbonate field example.

In the next step, we apply bed-by-bed joint inversion to the same depth interval in field example no. 1. After detecting bed-boundary locations based on density and PEF logs, separate inversion of logs yields physical properties for each bed including bed-by-bed density, migration length, electrical resistivity (or conductivity), and photoelectric factor (Figure 3). We observe relative differences as high as $37 \%$ in the estimates of migration length compared to center-bed values from logs in thin beds. Next, we take the results obtained from depth-by-depth nonlinear joint inversion of well logs as the initial guess for joint inversion to estimate bed-by-bed petrophysical and compositional properties.

Figure 4 compares measured well logs against their numerical simulations obtained using final results of bed-by-bed nonlinear joint inversion; it also compares the volumetric concentrations of minerals and fluids obtained with commercial software to those yielded by bed-by-bed nonlinear joint inversion. Borehole acoustic measurements were invoked to investigate vertical heterogeneity. The difference between measured compressional-wave slowness and estimated bed-by-bed values can be used as an indicator of
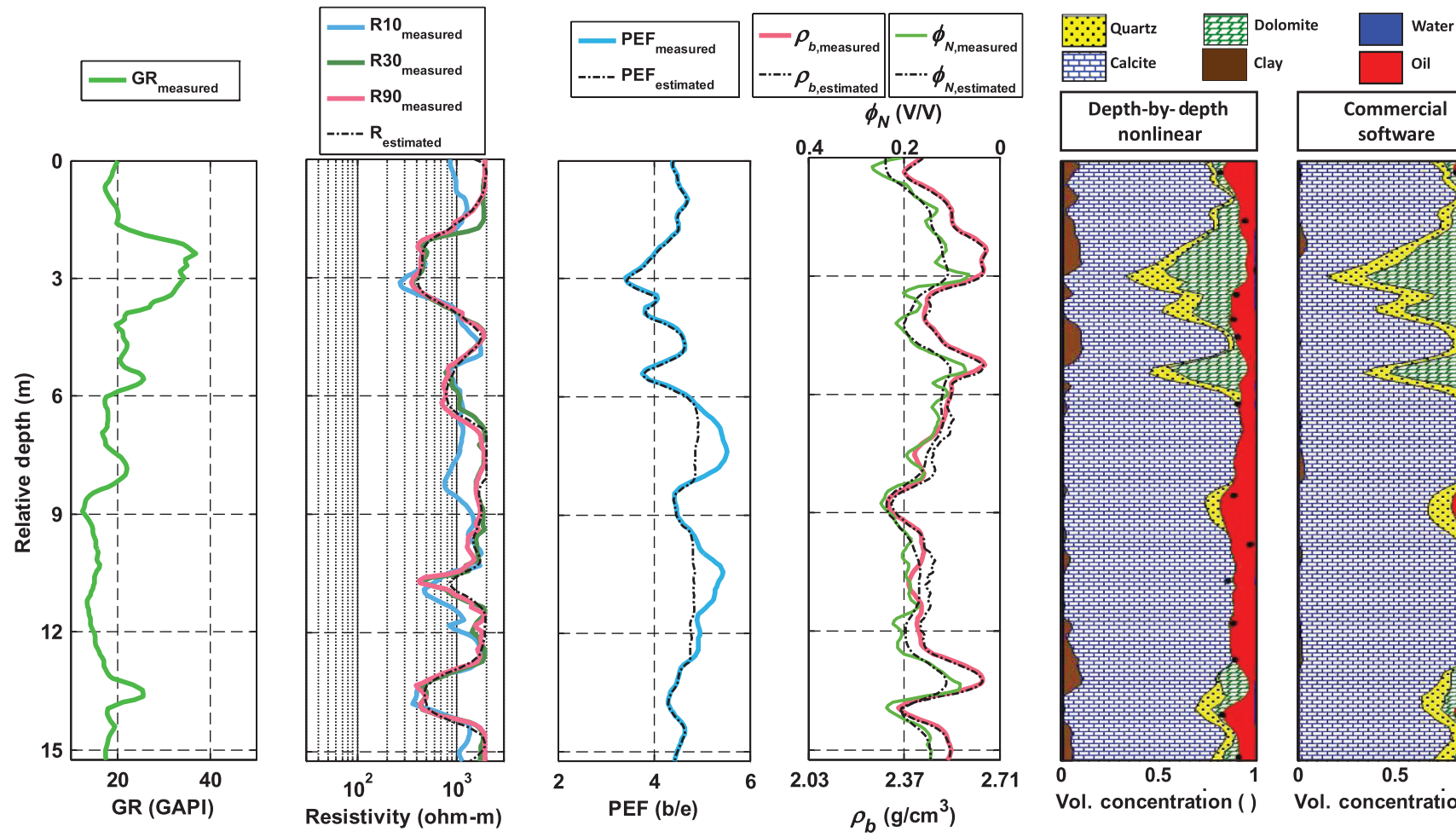

Figure 1. Carbonate field example no. 1: Comparison of final simulated well logs (black dash-dotted line) and measured logs (solid line). Results are shown for array induction resistivity (second left panel), PEF (third left panel), density and neutron porosity (water-filled limestone porosity units, fourth left-hand panel) well logs. The first two right-hand panels describe volumetric concentrations of mineral constituents, porosity, and fluid saturations obtained with commercial software and nonlinear depth-by-depth joint inversion of resistivity, PEF, density, and neutron porosity logs. Black dots identify porosity values reported from core measurements. 
heterogeneity which could indicate lack of pore connectivity. We estimated compressional-wave slowness using Wyllie's equation (Wyllie et al., 1956) and compared those estimates to measured values (Figure 4, second left-hand panel). The agreement between measured compressional-wave slowness and estimated bed-by-
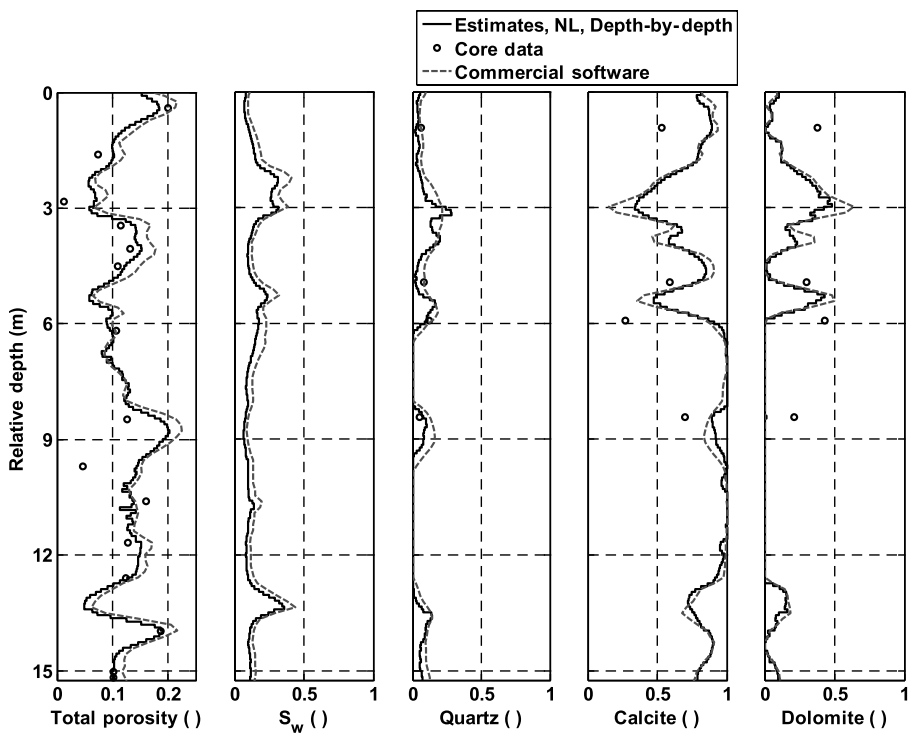

Figure 2. Carbonate field example no. 1: Comparison of total porosity, total water saturation, and solid volumetric concentrations of mineral constituents estimated with the depth-by-depth nonlinear joint inversion method (solid line), commercial software (dashed line), and core measurements (black circles). Panels from left to right show total porosity, total water saturation, and solid volumetric concentrations of quartz, calcite, dolomite, and clay.

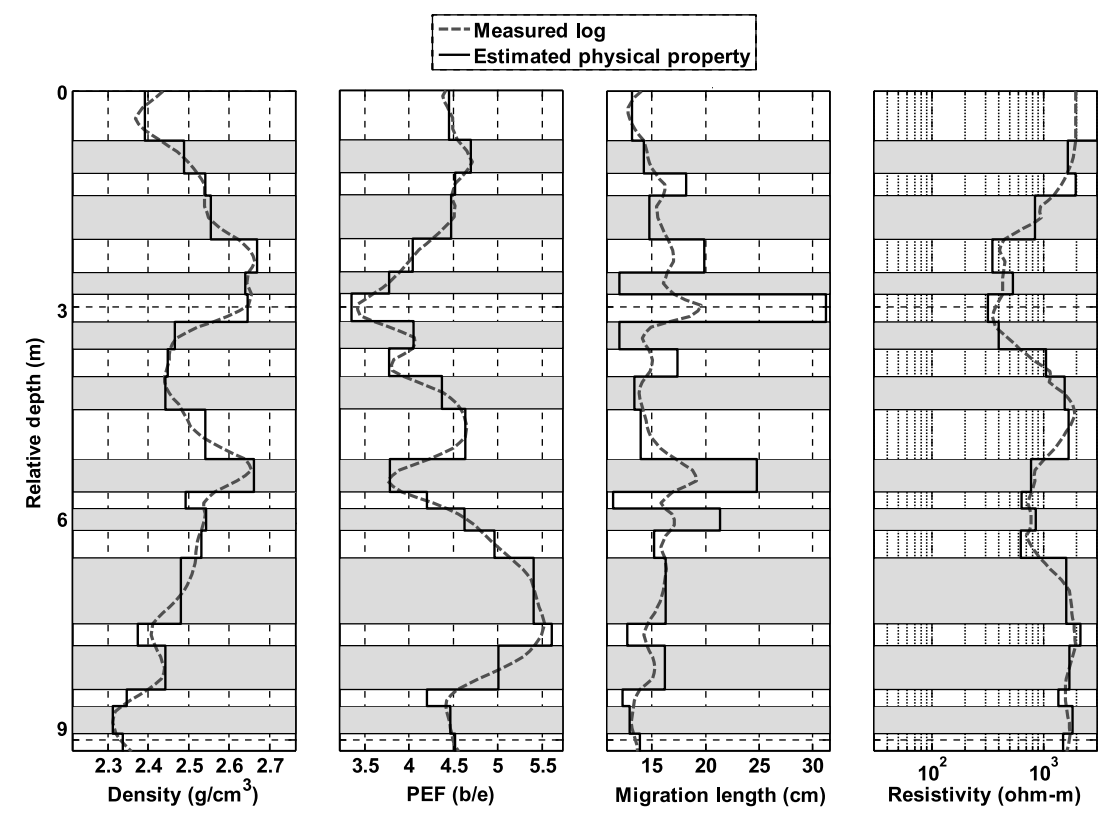

Figure 3. Carbonate field example no. 1: Comparison of measured logs (dashed line) and bed physical properties estimated with separate inversion of well logs (solid line). Panels from left to right show density, PEF, neutron migration length, and electrical resistivity.

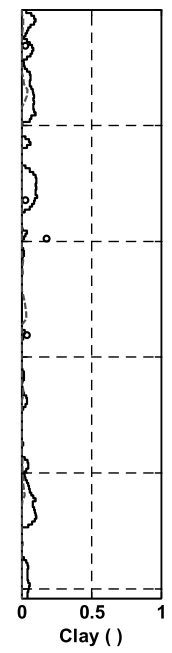

bed values could, among other things, suggest negligible nonconporosity in this depth interval. However, reliable assessment niques and especial core measurements.

Figure 5 compares results obtained with bed-by-bed nonlinear joint inversion against core/XRD measurements and results obtained with commercial software. We observe a significant improvement in the assessment of porosity with bed-by-bed joint inversion compared to commercial software (relative improvement of up to $140 \%$ in thin beds) and depth-by-depth joint inversion (relative improvement of up to $100 \%$ in thin beds) in the thinly bedded depth zone. Core photographs from the top $6.10-\mathrm{m}(20-\mathrm{ft})$ zone confirm the presence of thin beds of sand and shale. However, neither commercial software nor depth-by-depth nonlinear inversion accurately detect actual petrophysical properties of this zone because input well logs do not exhibit high vertical resolution. The improvement in estimates of porosity using bedby-bed joint inversion confirms the significance of implementing petrophysical and compositional interpretation methods that explicitly account for shoulder-bed effects on well logs. However, the uncertainty of inversion products is not negligible. Error (uncertainty) bars for inversion products in each bed were calculated by adding $2 \%$ zero-mean Gaussian random noise to all well $\operatorname{logs}$ input to the inversion (Figure 5). Results from this exercise indicate that the uncertainty in estimates of petrophysical and compositional properties increases with decreasing bed thickness as well as across subsequent thin beds.

\section{FIELD EXAMPLE NO. 2}

Field example no. 2 considers a hydrocarbonbearing carbonate formation. Based on sedimentological studies, reservoir facies consist of sandstone, mixed sandstone, dolostone, pelecypod limestone, foraminiferal limestone-siltstone, and shale, deposited in a shallow-marine carbonate platform. Presence of a variety of minerals in the formation makes it difficult to estimate porosity with conventional methods. Possible inaccuracies in the estimation of volumetric concentrations of mineral constituents may lead to measurable errors in the assessment of porosity and water saturation. Drilling mud is water-base mud (WBM) and well logs were sampled at a rate of $0.15 \mathrm{~m}(0.5 \mathrm{ft})$. Table 2 summarizes the average petrophysical properties assumed for the oilbearing bed in this field example. Average values of porosity, water saturation, and volumetric concentration of shale are used as a uniform, constant guess to initialize the nonlinear inversion. The rock is also assumed to be composed of pure dolomite as part of the initialization of nonlinear inversion. 
Core measurements indicate that the formation exhibits very low permeability and porosity. On the other hand, the separation between shallow and deep dual laterolog resistivity logs is negligible and there is no crossover between neutron porosity and density logs. We may thus assume that mud-filtrate invasion is either very deep or very shallow whereby the corresponding differential effect on well logs is negligible. Table 3 summarizes the assumed Archie's parameters and matrix, fluid, and formation properties. Well logs available for nonlinear inversion are GR, dual laterolog resistivity, density, and neutron porosity. Due to presence of barite in the mud, the PEF log is not reliable in this example.

The mineralogical composition reported from laboratory measurements indicates that the rock matrix includes dolomite, quartz, calcite, siderite, pyrite, and $K$-feldspar, with illite as the predominant clay type. This analysis is available at a few points in the depth zone of interest with an implicit absolute measurement error of \pm 0.15 for volumetric mineral concentrations. Because the average weight concentrations of pyrite and $K$-feldspar are lower than 0.04 in the depth zone of interest, we neglect them in the nonlinear inversion. This choice helps to reduce significant nonuniqueness in the estimation.

We observe that resistivity values in layers 2 and 6 (Figure 6) suddenly increase to
$500 \mathrm{ohm}-\mathrm{m}$, but this sharp change is not detected in other well logs. Presence of nonconnected porosity could be the reason for such a behavior. The physics of resistivity measurements is conducive to the detection of interconnected porosity, while that of density and

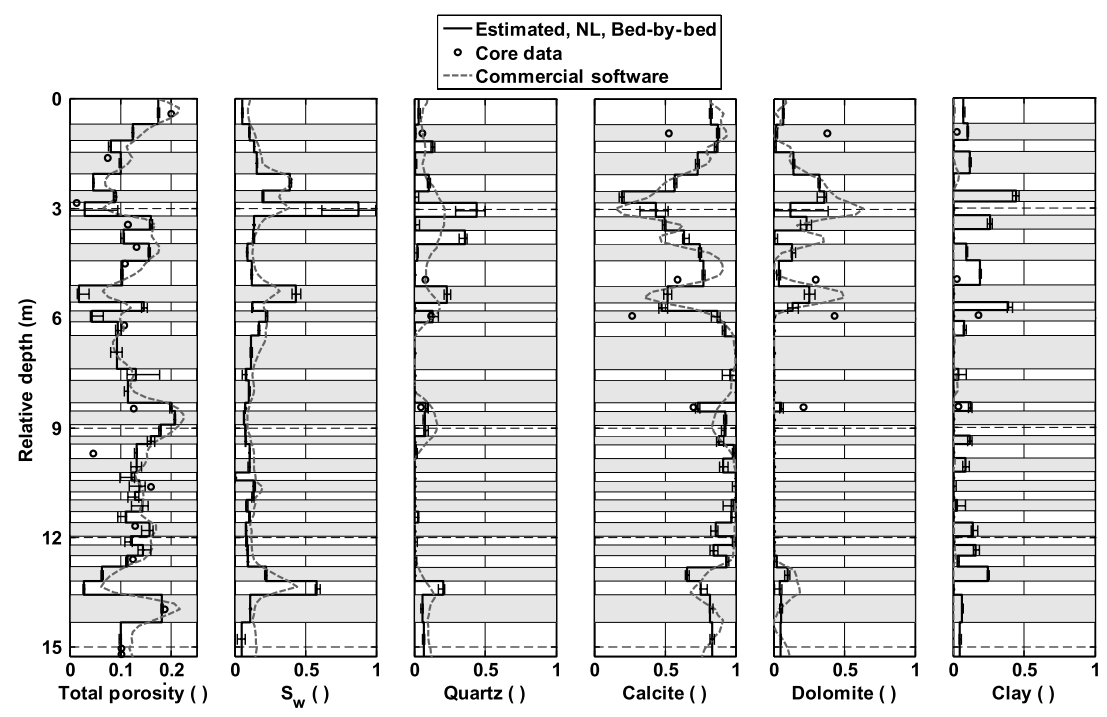

Figure 5. Carbonate field example no. 1: Comparison of total porosity, total water saturation, and solid volumetric concentrations of mineral constituents estimated with bedby-bed nonlinear joint inversion method (solid line), commercial software (dashed line), and core measurements (black circles) to corresponding uncertainty bars (calculated by adding 2\% zero-mean Gaussian random perturbations on input well logs). Panels from left to right show total porosity, total water saturation, and solid volumetric concentrations of quartz, calcite, dolomite, and clay.
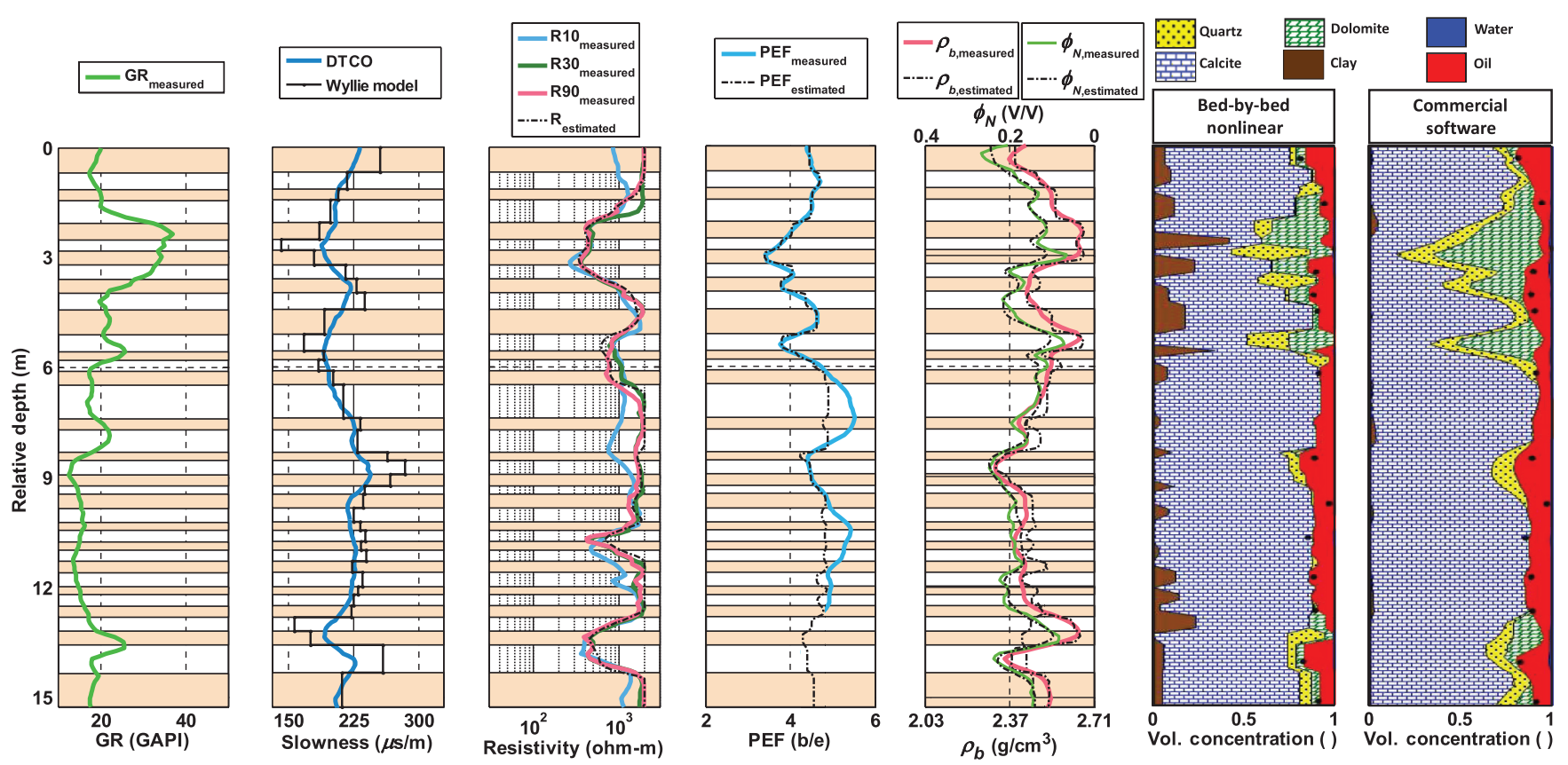

Figure 4. Carbonate field example no. 1: Comparison of final simulated well logs (black dash-dotted line) and measured logs (solid line). Results are shown for array induction resistivity (third left panel), PEF (fourth left panel), density and neutron porosity (water-filled limestone porosity units, fifth left panel) well logs. The second panel compares compressional-wave slowness against results obtained with Wyllie's model. The first two right panels describe volumetric concentrations of mineral constituents, porosity, and fluid saturations obtained with commercial software and nonlinear bed-by-bed joint inversion of resistivity, PEF, density, and neutron porosity logs. Black dots identify porosity values reported from core measurements. 
neutron porosity logs is conducive to the detection of total porosity. Therefore, it is possible that the inversion underestimates resistivity values across those layers.

Figure 6 compares the measured well logs to those obtained from final inversion products. The same figure compares volumetric concentrations of mineral constituents and petrophysical properties obtained with nonlinear inversion against mineralogical and porosity measurements performed on core samples and estimations obtained with commercial linear inversion software. Relative data misfits are $0.87 \%, 8.99 \%, 0.19 \%$, and $2.09 \%$ for GR, electrical conductivity, density, and neutron porosity logs, respectively. Table 4 describes the final estimates of nonshale porosity and water saturation in permeable layers.

Even though the PEF log is not available for inversion, estimates of porosity and volumetric concentrations of mineral constituents obtained with nonlinear inversion agree well with those of core measurements. On the other hand, the commercial linear method overestimates porosity by a factor of three. It is likely that the biased estimations of petrophysical properties and volumetric mineral concentrations obtained with commercial linear estimation software are due to unaccounted shoulder-bed effects or unaccounted nonlinear relationship between formation petrophysical and compositional properties and well logs. Even though the zone of interest

Table 2. Carbonate field example no. 2: Summary of calculated average petrophysical properties.

\begin{tabular}{llc}
\hline Variable & \multicolumn{1}{c}{ Value } & Units \\
\hline Thickness & $8.53(28 \mathrm{ft})$ & $\mathrm{m}$ \\
Absolute permeability, $k$ & 0.46 & $\mathrm{mD}$ \\
Nonshale porosity, $\phi_{s}$ & 0.057 & - \\
Volumetric concentration of shale, $C_{\mathrm{sh}}$ & 0.25 & - \\
\hline
\end{tabular}

Table 3. Carbonate field example no. 2: Summary of assumed Archie's parameters and matrix, fluid, and formation properties.

\begin{tabular}{lcc}
\hline Variable & Value & Units \\
\hline Winsauer factor in Archie's equation, $a$ & 1.00 & - \\
Archie's porosity exponent, $m$ & 2.00 & - \\
Archie's saturation exponent, $n$ & 2.00 & - \\
Connate-water salt concentration & 125 & $\mathrm{kppm} \mathrm{NaCl}$ \\
Mud filtrate resistivity at $194^{\circ} \mathrm{F}$ & 0.09 & $\mathrm{ohm}-\mathrm{m}$ \\
Water density & 1.00 & $\mathrm{~g} / \mathrm{cm}^{3}$ \\
Water viscosity & 1.00 & $\mathrm{cp}$ \\
In situ oil density & 0.70 & $\mathrm{~g} / \mathrm{cm}^{3}$ \\
Formation temperature & 194 & ${ }^{\circ} \mathrm{F}$ \\
Wet clay density & 2.54 & $\mathrm{~g} / \mathrm{cm}^{3}$ \\
Wellbore radius & 10.63 & $\mathrm{~cm}^{3}$ \\
\hline
\end{tabular}

is a hydrocarbon-bearing depth interval with no water production, the two commercial inversion methods estimate average water saturation higher than 0.50 , which can be due to deep WBM invasion. Nonlinear inversion is also unable to estimate initial water saturation in this case if mud-filtrate invasion is very deep, which makes resistivity logs insensitive to dynamic petrophysical properties.

\section{FIELD EXAMPLE NO. 3}

Field example no. 3 is another hydrocarbon-bearing carbonate formation. Core measurements indicate that porosity and permeability vary in the range of $0.15-0.20$ and 3-23 md, respectively, in the zone of interest. Available conventional well logs are PEF, GR, density, neutron porosity, and laterolog electrical resistivity with a sampling rate of $0.15 \mathrm{~m}(0.5 \mathrm{ft})$. Drilling mud is WBM. The inversion is initialized with average porosity, water saturation, and volumetric concentration of shale calculated with conventional petrophysical interpretation techniques (Table 5). Mineral types are usually identified based on available XRD data. However, in this field example, XRD data are not available. Thus, we assume that the formation contains common rock minerals found in carbonate formations including quartz, dolomite, and calcite. Clay type is also assumed to be illite. Initial guesses for volumetric concentrations of mineral constituents are arbitrarily chosen to be equal to each other. In this field example, the choice of initial guess is not crucial because the inverse problem is even-determined (PEF is reliable and, consequently, the number of available well logs is equal to the number of unknown properties).

The separation between shallow and deep dual laterolog resistivity $\log$ s is negligible. Consequently, we assume that mud-filtrate invasion is either very deep or very shallow and that its corresponding differential effect on well logs is not significant. Table 6 lists the assumed Archie's parameters and matrix, fluid, and formation properties in this example.

Figure 7 compares the measured well logs to their numerical simulations. The same figure shows final petrophysical and compositional estimates obtained with commercial software and those obtained with nonlinear inversion. Relative data misfits are $0.34 \%$, $2.10 \%, 3.94 \%, 0.69 \%$, and $2.18 \%$ for GR, PEF, electrical conductivity, density, and neutron porosity logs, respectively. Table 7 compares final estimates of total porosity obtained with nonlinear inversion to core measurements in permeable layers where they are available. Presence of nonconnected porosity in this formation could be the reason for estimated porosity values to be lower than those of core measurements.

Estimates of volumetric concentration of mineral constituents obtained with nonlinear joint inversion and commercial software are different. However, there are no XRD data available to validate either set of estimates. Experience shows that mineralogy results obtained with commercial software can be highly dependent on core/XRD-based calibrations. In the absence of XRD/core data, petrophysical and compositional properties obtained with commercial software might be unreliable. By contrast, the nonlinear joint inversion technique implemented in this paper does not require core/XRD data for calibration. Consequently, the absence of core/XRD measurements does not significantly affect the results obtained with nonlinear joint inversion of well logs. 


\section{DISCUSSION}

This paper documents the application of nonlinear joint inversion methods introduced by Heidari et al. (2012) to three carbonate formations with complex solid composition and thin beds. Results obtained for these examples are compared to results obtained with commercial software. Inputs to inversion include any combination of conventional well logs such as density, neutron porosity, electrical resistivity, GR, and PEF, as well as formation properties such as Archie's parameters, in situ fluid properties, and type and chemical formula of available minerals. We show that even in the absence of PEF logs, comparison of estimates for porosity, water saturation, and volumetric concentrations of mineral constituents against core/XRD data indicated relative improvements of more than $30 \%$ in the assessment of porosity using the new methods compared to commercial software (field example no. 2). Estimates of water saturation, however, are not reliable in the presence of very deep WBM-filtrate invasion (field example no. 2).

Field example no. 1 shows a significant improvement in the assessment of petrophysical properties in thinly bedded formations (up to $100 \%$ relative improvement in porosity estimates) when using bed-by-bed joint inversion (which explicitly takes into account shoulder-bed effects on well logs). Furthermore, we show that joint inversion methods enable the diagnosis of unreliable well logs and sources of uncertainty (e.g., presence of minerals that are not taken into account as input parameters and presence of nonconnected porosity) in the earth model.

A unique advantage of the nonlinear joint inversion methods implemented in this paper is their nonreliance on XRD/core data for calibration. Commercial multimineral software requires XRD data for calibration when assessing volumetric/weight concentrations of mineral constituents. Interpretation results from commercial software can be unreliable in the absence of XRD/core measurements and model calibration. Both inversion-based interpretation methods implemented in this paper, depth-by-depth and bed-bybed nonlinear joint inversion, do not require mineral/fluid calibration. The nonreliance on calibration methods comes from the fact that we estimate physical properties of minerals/fluids based on their volumetric concentration and chemical formulas using SNUPAR.

In field example no. 2, volumetric concentration of clay estimated with nonlinear joint inversion is greater than values reported by

Table 4. Carbonate field example no. 2: Nonlinear inversion results obtained for porosity and water saturation in each layer.

\begin{tabular}{ccll} 
Layer no. & Layer thickness $(\mathrm{m})$ & \multicolumn{1}{c}{$\phi_{s}$} & $S_{w}$ \\
\hline 1 & $1.07(3.5 \mathrm{ft})$ & 0.001 & 0.45 \\
2 & $0.76(2.5 \mathrm{ft})$ & 0.08 & 0.17 \\
3 & $0.91(3.0 \mathrm{ft})$ & 0.02 & 0.64 \\
4 & $0.61(2.0 \mathrm{ft})$ & 0.05 & 0.34 \\
5 & $1.07(3.5 \mathrm{ft})$ & 0.09 & 0.21 \\
6 & $1.22(4.0 \mathrm{ft})$ & 0.07 & 0.15 \\
7 & $0.76(2.5 \mathrm{ft})$ & 0.04 & 0.57 \\
\hline
\end{tabular}
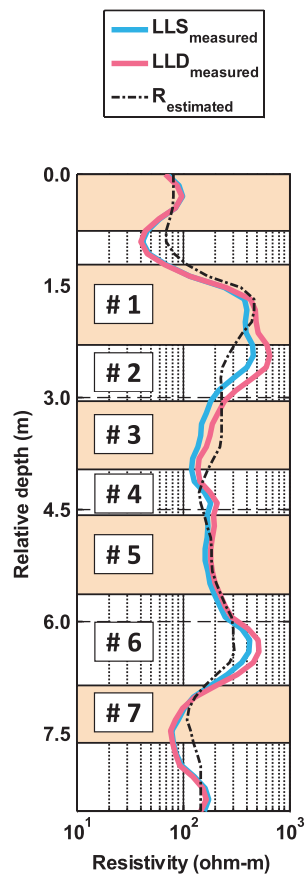
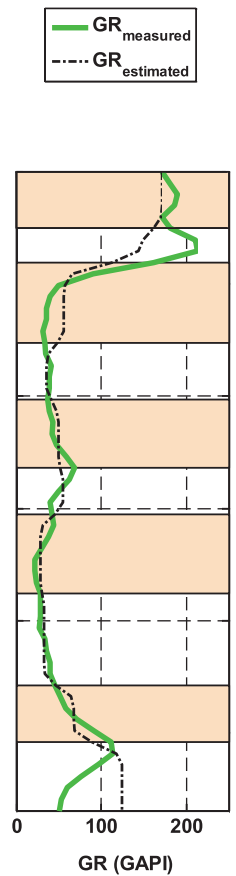
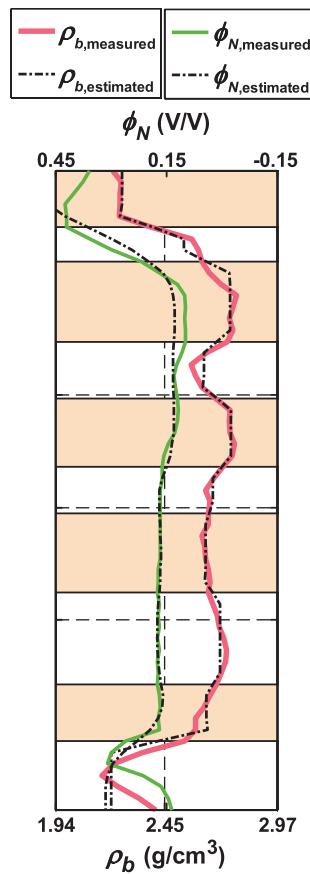
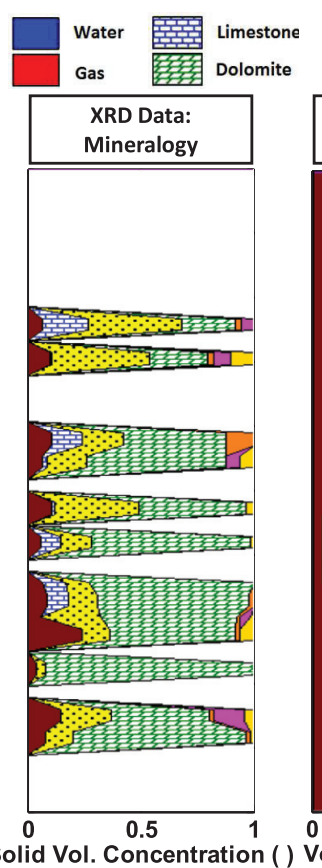
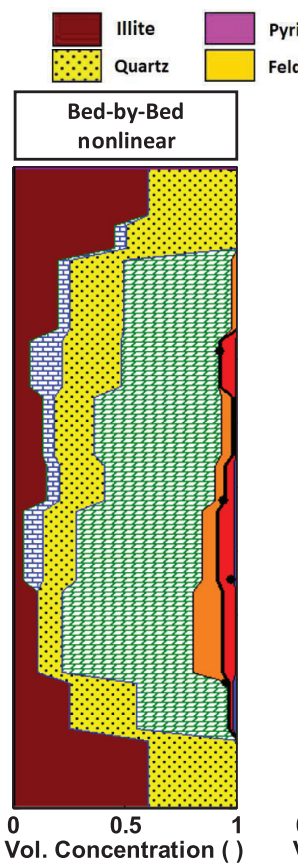

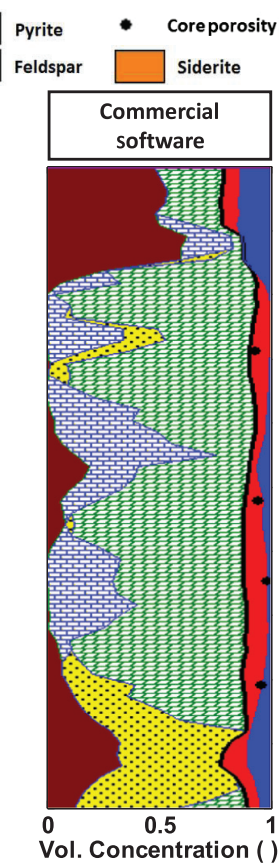

Figure 6. Carbonate field example no. 2: Comparison of final simulated well logs (black dash-dotted line) and measured logs (solid line). Results are shown for dual laterolog resistivity (left panel), GR (second left panel), density and neutron porosity (water-filled limestone porosity units, third left panel) well logs. The center panel shows solid volumetric concentrations of mineral components obtained with mineralogical analysis. The first right panel describes volumetric concentrations of mineral constituents, porosity, and water saturation obtained with commercial software. The second right panel describes the same properties obtained with nonlinear joint inversion of resistivity, density, neutron porosity, and GR logs. 
Table 5. Carbonate field example no. 3: Summary of calculated average petrophysical properties.

\begin{tabular}{lcc} 
Variable & Value & Units \\
\hline Thickness & $21.64(71 \mathrm{ft})$ & $\mathrm{m}$ \\
Absolute permeability, $k$ & 20 & $\mathrm{mD}$ \\
Nonshale porosity, $\phi_{s}$ & 0.19 & - \\
Volumetric concentration of shale, $C_{\mathrm{sh}}$ & 0.15 & - \\
\hline
\end{tabular}

Table 6. Carbonate field example no. 3: Summary of assumed Archie's parameters and matrix, fluid, and formation properties.

\begin{tabular}{lcc}
\hline Variable & Value & Units \\
\hline Winsauer factor in Archie's equation, $a$ & 1 & - \\
Archie's porosity exponent, $m$ & 1.5 & - \\
Archie's saturation exponent, $n$ & 2 & - \\
Connate-water salt concentration & 200 & $\mathrm{kppm} \mathrm{NaCl}$ \\
Water density & 1.0 & $\mathrm{~g} / \mathrm{cm}^{3}$ \\
Water viscosity & 1.0 & $\mathrm{cp}^{3}$ \\
In situ oil density & 0.8 & $\mathrm{~g} / \mathrm{cm}^{3}$ \\
Formation temperature & 210 & ${ }^{\circ} \mathrm{F}$ \\
Wet clay density & 2.54 & $\mathrm{~g} / \mathrm{cm}^{3}$ \\
Wellbore radius & 15.5 & $\mathrm{~cm}^{3}$ \\
\hline
\end{tabular}
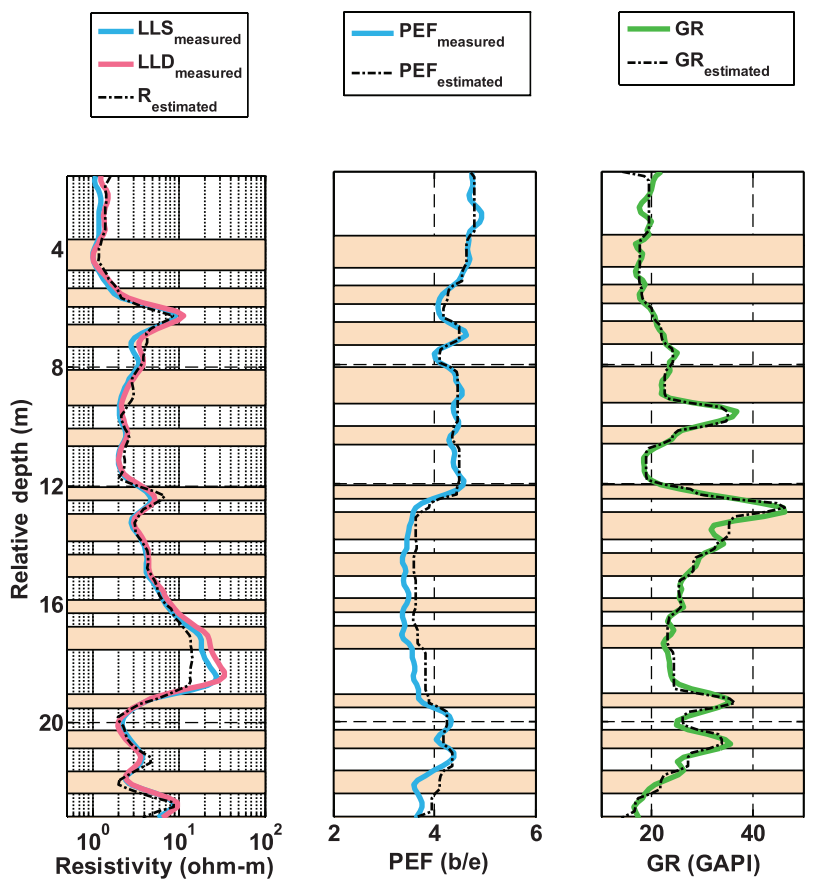

XRD measurements. Such a difference was expected because XRD measurements usually underestimate clay concentration (Sondergeld et al., 2010). Comparison of results obtained with bed-bybed nonlinear joint inversion against commercial software indicates a significant difference in all the field examples. This behavior can be explained by the complex solid composition present in the three field examples as well as thin beds and shoulder-bed effects on well $\log$ in the first and second field example.

Presence of nonconnected porosity in carbonate reservoirs is challenging in the assessment of petrophysical properties from well logs. Even though, in some cases, it is possible to quantify the effects of nonconnected and interconnected porosity on well logs, the assessment of nonconnected porosity is not accurate in underdetermined inversion. Inverse problems considered in this study were underdetermined in field example nos. 1 and 2 , and evendetermined in field example no. 3. Including an additional unknown (e.g., nonconnected porosity) in the estimation renders the inversion underdetermined thereby giving rise to nonuniqueness of results. Sonic measurements are good candidates for crossvalidation of estimated petrophysical properties to confirm whether the effect of nonconnected porosity on well logs is negligible (field example no. 1). If the effect of nonconnected porosity is not negligible, then nonconnected porosity itself should be considered as one of the unknown properties in the inversion.

Similar to results reported by Heidari et al. (2012), CPU times associated with the processing of a 15.24-m (50-ft) formation with 25 beds and sampling depth interval of $0.076 \mathrm{~m}(0.25 \mathrm{ft})$ are $10 \mathrm{~min}$ and $1 \mathrm{~h}$ for depth-by-depth and bed-by-bed nonlinear joint inversion methods, respectively, when implemented on a $\mathrm{PC}$ with a $3 \mathrm{GHz}$ processor and 4 GB RAM. The low CPU times for both of these
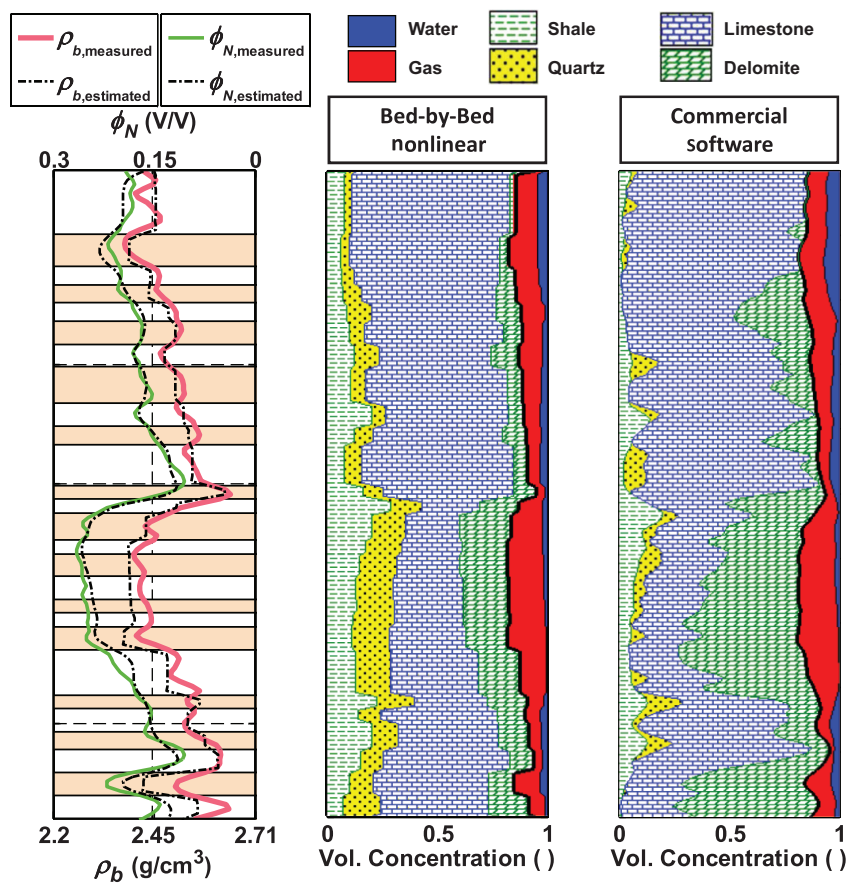

Figure 7. Carbonate field example no. 3: Comparison of final simulated well logs (black dash-dotted line) and measured logs (solid line). Results are shown for dual laterolog resistivity (left panel), PEF (second left panel), GR (third left panel), density and neutron porosity (waterfilled limestone porosity units, fourth left panel) well logs. The first right panel describes volumetric concentrations of mineral constituents, porosity, and water saturation obtained with commercial software. The second right-hand panel describes the same properties obtained with nonlinear joint inversion of resistivity, density, neutron porosity, and GR logs. 
Table 7. Carbonate field example no. 3: Nonlinear inversion results obtained for porosity and water saturation in each layer. techniques make it feasible to implement them in multiple-well case studies.

We emphasize that the inversion-based methods documented in this paper rely on predefined bed-boundary locations. Inaccuracy in bed-boundary locations leads to uncertainty in final estimates of volumetric concentrations of minerals and petrophysical properties. In a previous publication, Heidari et al. (2012) report possible errors of more than $30 \%$ in beds as thick as four times one log-sampling interval, if the assumed bed boundaries are perturbed by one logsampling interval. However, the corresponding effect on inverted properties depends not only on bed-boundary locations (Heidari and Torres-Verdín, 2012), but also on bed thickness and the specific petrophysical and compositional properties of the bed.

\section{CONCLUSIONS}

The successful application of our recently introduced inversionbased interpretation methods of well logs to three challenging carbonate formations confirms the reliability of these methods for petrophysical and compositional evaluation of formations with complex solid composition and thin beds. Comparison of estimates yields by bed-by-bed nonlinear joint inversion against results obtained with commercial software and core/XRD data emphasizes the need for correction of shoulder-bed effects on well logs across thinly bedded formations. Neglecting this correction in thin beds can lead to $100 \%$ and $60 \%$ relative error in the assessment of porosity and water saturation, respectively.

Advantages of the new methods over historical and current commercial well-log interpretation and multimineral methods include (1) the possibility of correcting for shoulder-bed effects on well logs based on numerical simulation, (2) nonreliance of inversion to $\mathrm{XRD} /$ core measurements for calibration purposes, and (3) evaluation of well-log and model reliability from inversion products.

\section{NOMENCLATURE}

$\begin{array}{ll}a & =\text { Winsauer factor in Archie's equation } \\ C_{\text {sh }} & =\text { Volumetric concentration of shale } \\ k & =\text { Absolute permeability, }(\mathrm{mD}) \\ m & =\text { Archie's porosity exponent } \\ n & =\text { Archie's saturation exponent } \\ S_{w} & =\text { Total water saturation } \\ \phi_{s} & =\text { Nonshale porosity } \\ \text { CPU } & =\text { Computer processing unit } \\ \text { DTCO } & =\text { Delta- } T \text { compressional slowness } \\ \text { FTIR } & =\text { Fourier transform infrared transmission }\end{array}$

$\begin{array}{ll}\text { GR } & =\text { Gamma ray } \\ \mathrm{kppm} & =\text { Kilo parts per million } \\ \mathrm{MID} & =\text { Matrix identification } \\ \mathrm{NL} & =\text { Nonlinear } \\ \mathrm{OBM} & =\text { Oil-base mud } \\ \mathrm{PEF} & =\text { Photo electric factor } \\ \mathrm{K} & =\text { Potassium } \\ \mathrm{SNUPAR} & =\text { Schlumberger nuclear parameter code } \\ \text { Th } & =\text { Thorium } \\ \mathrm{U} & =\text { Uranium } \\ \text { WBM } & =\text { Water-base mud } \\ \text { XRD } & =\text { X-ray diffraction } \\ \text { XRF } & =\text { X-ray fluorescence }\end{array}$

\section{ACKNOWLEDGMENTS}

The work reported in this paper was funded by The University of Texas at Austin's Research Consortium on Formation Evaluation, jointly sponsored by Anadarko, Apache Corporation, Aramco, Baker Hughes, BG, BHP Billiton, BP, Chevron, ConocoPhillips, ENI, ExxonMobil, Halliburton, Hess, Maersk, Marathon, Mexican Institute for Petroleum, Nexen, Pathfinder, Petrobras, Repsol, RWE, Schlumberger, Statoil, TOTAL, and Weatherford. We are indebted to Chris Skelt and two anonymous reviewers for their constructive technical and editorial suggestions which improved the quality of the original manuscript.

\section{REFERENCES}

Clavier, C., and D. H. Rust, 1976, MID-plot: A new lithology technique: The Log Analyst, 17, no. 6, 16-24.

Doveton, J. H., 1994, Geologic log analysis using computing methods: AAPG Computer Applications in Geology, no. 2.

Heidari, Z., and C. Torres-Verdín, 2012, Improved detection of bed boundaries for petrophysical evaluation with well logs: Applications to carbonate and organic-shale formations: Proceedings of the SPE Annual Technical Conference and Exhibition, SPE 159197.

Heidari, Z., C. Torres-Verdín, and W. E. Preeg, 2012, Improved estimation of mineral and fluid volumetric concentrations from well logs in thinlybedded and invaded formations: Geophysics, 77, no. 3, WA79-WA98, doi: 10.1190/geo2011-0454.1.

Herron, M. M., S. L. Herron, J. A. Grau, N. V. Seleznev, J. Philips, A. E. Sherif, S. Farag, J. P. Horkowtiz, T. J. Neville, and K. Hsu, 2002, Realtime petrophysical analysis in siliciclastics from the integration of spectroscopy and triple-combo logging: Proceedings of the SPE Annual Technical Conference and Exhibition, SPE 77631.

Herron, S. L., and M. M. Herron, 1996, Quantitative lithology: An application for open and cased hole spectroscopy: 37th Annual Logging Symposium, SPWLA, Paper E.

Mayer, C., and A. Sibbit, 1980, Global, a new approach to computerprocessed log interpretation: Proceedings of the SPE Annual Technical Conference and Exhibition, SPE 9341.

Quirein, J., S. Kimminau, J. LaVigne, J. Singer, and F. Wendel, 1986, A coherent framework for developing and applying multiple formation evaluation models: 27th Annual Logging Symposium, SPWLA, Paper DD.

Rabaute, A., A. Revil, and E. Brosse, 2003, In situ mineralogy and permeability logs from downhole measurements: Application to a case study in clay-coated sandstone formations: Journal of Geophysical Research 108, 2414, 1-16, doi: 10.1029/2002JB002178.

Schlumberger log interpretation charts, 2009: Schlumberger

Sondergeld, C. H., K. E. Newsham, J. T. Comisky, M. C. Rice, and C. S. Rai, 2010, Petrophysical considerations in evaluating and producing shale gas resources: Proceedings of the SPE Unconventional Gas Conference, SPE 131768

Wyllie, M. R. J., A. R. Gregory, and L. W. Gardner, 1956, Elastic wave velocities in heterogeneous and porous media: Geophysics, 21, 41-70, doi: $10.1190 / 1.1438217$. 